\title{
FINGERPRINT: MACHINE TOOL CONDITION MONITORING APPROACH FOR ZERO DEFECT MANUFACTURING
}

\author{
M. Armendia ${ }^{1 *}$, J. San Sebastian², D. Gonzalez¹, B. Santamaria1, J. A. Gonzalez ${ }^{1}$ \\ R. Gonzalez-Velazquez ${ }^{1}$, K. Lopez de Calle ${ }^{1}$ \\ 1 Tekniker, Basque Research and Technology Alliance (BRTA), C/ Inaki Goenaga, 5, 20600 Eibar, Spain \\ 2 Gamesa Energy Transmission, Zona Industrial Pol., 83, 20159 Asteasu, Spain \\ *Corresponding author; e-mail: mikel.armendia@tekniker.es
}

\begin{abstract}
Manufacturing process monitoring is showing great advances thanks to increasing sensor availability and the development of edge to cloud loT systems. However, the application of this technology in industry is slowed down due to cyber security policies, the coexistence of old manufacturing systems, with limited monitoring capabilities, with newer and fully monitored ones, and the lack of application-oriented functionalities. In this paper, a fast and automated machine tool characterization procedure, called Fingerprint, is presented, that allows determining useful Key Performance Indicators of the status of machine tools based on loT technologies. The paper also presents the implementation of this technology in industrial environment.
\end{abstract}

\section{Keywords:}

Machine Tool, Zero Defect Manufacturing, Condition Monitoring, Health Assessment

\section{INTRODUCTION}

The machine tool sector has been demanding for several decades the monitoring of the production process and the use of the data acquired to improve the production process. It is an old aspiration that has been covered in recent years by the so-called Industry 4.0 [Zhong 2017, Zheng 2018]. Thus, the latest generation machining centers incorporate sensors that capture internal signals from the machine tool (like positions, speeds, power) and integrate sensors to measure other variables of interest (like vibrations, temperatures).

There are also more and more connectivity devices (Edge systems, Gateways ... the name changes depending on the level of action) that allow to collect and manage this information available at the controls. These systems can be incorporated by CNC suppliers (SIEMENS Sinumerik Edge), machine tool manufacturers (Celos by DMG Mori) or even third-party systems (ARTIS, SAAVY, etc.). These systems, in addition to collecting information of interest, allow sending information to centralized systems on servers or even in the cloud.

Despite this significant evolution, in most cases, these systems are only limited to collecting information and providing rough production related Key Performance Indicators (KPIs): total power consumption, number of machined references, etc. Few applications use the collected information to determine more elaborated, and useful, data and apply it to optimize the manufacturing performance. Furthermore, the application of this type of technology in small and medium-sized companies is still an utopia, since they do not have the economic possibilities to renew their machinery [Frank 2019]. In this way, the need to apply the Industry 4.0 concept in manufacturing processes still arises, adapting it to the possibilities of the multiple machining companies in the sector.

These loT technologies are the basis for the Zero Defects Manufacturing paradigm [Psarommatis 2019], since they provide information that can be used to determine the behavior of the manufacturing process as well as of the machine that performs it. For example, part quality is directly affected by phenomena such as drive backlash [Wang 2015].

Normally, the machine tool supplier performs a series of measurements on the machine as validation tests, ranging from the geometric characterization of errors to the dynamic characterization of the drives. For example, in [Schwenke 2008] different tests for the geometric characterization of machine tools are collected, classified as direct and indirect. Direct techniques allow measuring a single error component in each trial. These techniques can be based on artifacts (squares, calibrated rulers, patterns ...), on laser systems (interferometry) or on gravity systems (inclinometers). Due to the flexibility to measure elements of different lengths, laser technologies are predominant in recent years. As for indirect techniques, used for the detection of overlapping errors of two or more axes, those based on artifacts and on contour measurement (ball-bar) can be found. All these techniques, especially the direct ones and, specifically, those based on laser interferometry involve long preparation and measurement times.

Regarding dynamic behavior of the machines, there are numerous tools that range from frequency analysis, such as modal analysis [Okubo 1982] and the obtention of transfer 
functions of the drives [Vesely 2009], to the usage of monitoring tools (oscilloscopes) to analyze in detail the control signals and validate the operation of the machine. Again, these procedures are normally complex and require external equipment, leading to the need for expert personnel.

These tests are normally carried out at the initial reception of the machine at the end-user's home and, barring major problems, they are rarely repeated. However, the reality is that the machine changes its behavior with its use and that critical variables related to the quality of the process, such as backlash, friction in the guides, etc. do not keep constant in time. For this reason, there is a need to design and implement a rapid and automated characterization procedure of the state of the main components of machine tools [Armendia 2019].

After the introduction, the second section presents the strategy adopted by the authors for the rapid characterization of the state of machine tools. The third section summarizes the implementation of the functionality in an industrial manufacturing plant. Finally, the fourth section presents the conclusions and next steps in this line of work.

\section{MACHINE TOOL FINGERPRINT}

\subsection{Overall approach}

Machine tool status changes with time, elements degrade leading to maintenance problems but also affect manufacturing process performance and, hence, part quality. The control of the condition of the machine tool will impact manufacturing performance in both maintenance and process control activities.

Data recorded during normal operation of the machine tools provides relevant production insights (manufactured part number, cycle times, power consumption, etc.). However, especially in machining processes, the impact of the manufacturing process in the recorded data is very high and it is difficult to isolate machine tool condition from it [Armendia 2016].

To overcome this issue, the authors propose to perform a repetitive and controlled sequence of movements, avoiding the effect of manufacturing process, that will provide relevant information about machine performance. To properly trace machine condition over time, the test, called Fingerprint for machine tools, needs to be fast, to avoid productivity reduction, and automated, to avoid new skill requirements for operators.

\subsection{Monitoring system}

The proposed functionality is based on a monitoring system that collects internal variables from the PLC of the machine. This monitoring system is prepared to collect data through Ethernet connection from the major CNC manufacturers (SIEMENS, Heidenhain, FAGOR, FANUC, etc.) and can also integrate data coming from external sensor, like accelerometers.
The monitoring system is able to collect data continuously for manufacturing control purposes (normally $1 \mathrm{~Hz}$ rate is enough) but, when a Fingerprint test is executed, it automatically detects it and changes the acquisition rate to properly monitor the test. Acquisition frequency is increased up to $50 \mathrm{~Hz}$, depending on the controller of the machine. In order to reach this cadence, OPC type communication is avoided, and proprietary protocols are used instead.

The monitoring system allows integration of postprocessing stages so that KPIs can be calculated after every test (Fig. 1). In addition, the system provides data upload possibilities to both local servers and cloud platforms.

\subsection{Test procedure}

As mentioned, a sequence of movements for machine tool axes and spindles have been defined and programmed in G-code. This sequence consists of:

- A back and forward movement with each of the studied machine tool axes. Programmed feedrate and displacement must ensure that a constant velocity regime is reached.

- A circular interpolation with each pair of studied linear axes, emulating a ball-bar test [Cep 2018].

- Rotation at constant velocity with each of the studied machine tool spindles. Usage of spindleintegrated accelerometers is considered, and it allows calculating more KPIs.

To execute the machine tool Fingerprint test, the operator only needs to load the part program that contains the movement sequence and execute it. Cycle time of the Fingerprint test depends on the stroke of the studied axes, but it is usually around 3 minutes. The impact in machine tool availability is negligible and the test can be easily included in a potential weekly maintenance activity plan.

\subsection{Post-processing}

Raw data acquired during the Fingerprint test is temporally stored and post-processed, so that useful KPls are calculated.

A Digital Twin of machine tool feed drives is used as a reference for raw data post-processing. A simplified twomass model of feed drives is applied, with motor inertia as the first mas and load inertia, reduced at motor shaft, as second mass. A rigid transmission is assumed, and backlash is considered between both masses. The following KPIs are obtained:

- Friction of each machine tool axis and spindle.

- Backlash of the feed drive of each axis.

- Maximum torque of each axis.

- Inversion peak of each axis

- Vibration indicators for spindles: RMS, peak, and different frequency bands depending on spindle bearing configuration.

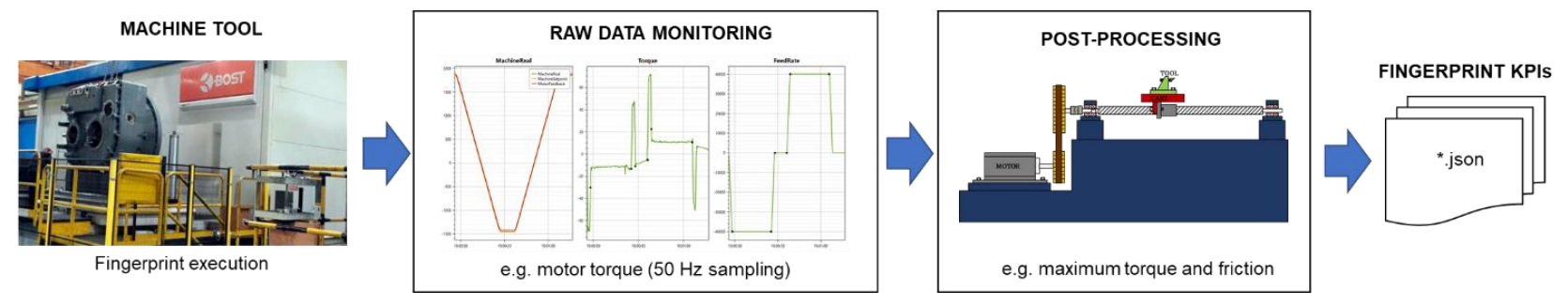

Fig. 1: Fingerprint KPI obtention procedure overview. 


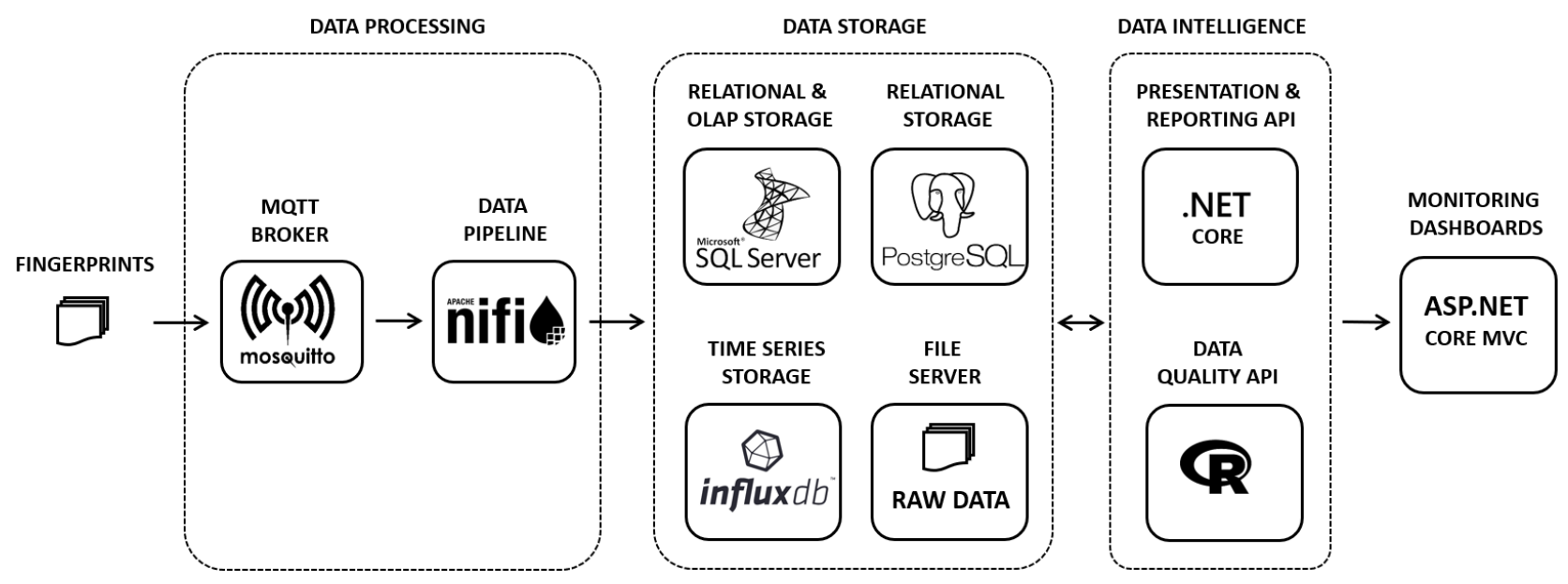

Fig. 2: Data management system implementation.

As can be observed, most KPIs have physical meaning so machine tool operators and maintenance technicians can easily relate its values with the condition of specific machine tool components.

\subsection{Data management and visualization}

KPIs are serialised into a JSON file that is locally stored but can also be automatically uploaded to a data management system located on the cloud. Fig. 2 shows the high-leve architecture of this platform.

Before being sent to the cloud, JSON files are converted into the MTConnect XML format. This means that data coming from different machines is structured into a standardized vocabulary and semantics, and fingerprints could be sent to a third party capable of parsing this information model.

Data is sent from the edge to the cloud through a Message Queue Telemetry Transport (MQTT) topic. The use of a local store on the edge and a remote topic on cloud makes the communication path more robust, preventing the loss of information over unreliable networks, and allowing a temporary interruption of the transmission for maintenance reasons.

MQTT is a lightweight loT publish/subscribe protocol, where messages are sent by publishers (the edge monitoring systems) and consumed by subscribers (the platform's processing data pipeline), via an intermediate MQTT broker (Eclipse Mosquitto). This middleware ensures a decoupling in the communication between publishers and subscribers, which improves the flexibility of the system, and the possibility of using load-balancing and autoscaling strategies when the number of messages received on the platform increases.

Message processing on the platform is done with a flowbased runtime environment (Apache $\mathrm{NiFi}$ ), which is a software application where logic is defined graphically by interconnecting a number of specific nodes. Flow-based programming fits very well in loT scenarios as part of integration architectures for the interoperation of systems and services. This programming paradigm promotes a highlevel, functional view of the processes, provides an inherently concurrent environment, and facilitates the testing, monitoring, and logging of processes.

Regarding storage, the platform follows a polyglot persistence pattern, where several types of repositories are created for the various aspects of data exploitation. The management of multiple databases to combine their advantages is a useful strategy in big data scenarios [Khine, 2019]. The platform uses a time series database (InfluxDB) for time series visualization capabilities, relational databases for storing medata, fingerprints (SQL Server), and data quality information (PostgreSQL), an OLAP database (SQL Server Analysis Services) for handling aggregated operational data, and a file server for raw file storage.

Tab. 1: Data quality metrics.

\begin{tabular}{ccc}
\hline Dimension & Metric & Problem identification \\
\hline Completeness & $\begin{array}{c}\text { Global Completeness } \\
\text { Completeness by Observations } \\
\text { Completeness by Variables }\end{array}$ & $\begin{array}{c}\text { Missing values } \\
\text { Missing observations } \\
\text { Missing variables }\end{array}$ \\
\hline Uniqueness & Time Uniqueness & Repeated timestamps \\
\hline Accuracy & Range & Out-of-range values \\
& Consistency & Typicality \\
& Moderation & Values out of the 80\% confidence interval \\
& Timeliness & Values out of the 95\% confidence interval \\
Timeliness & Names & Excessive waiting time between observations \\
\hline Conformity & Format & Wrong variable names \\
& & Different data formats
\end{tabular}


Data quality management is performed at different levels in the platform. Fingerprint tests are checked as they arrived in the system for missing data and outliers in the values. When an issue is detected in a fingerprint, a notification is shown in the application interface prompting the user to repeat the test. In addition to in-line data quality checks, a batch process is executed periodically on a weekly basis to calculate a data quality index for each machine with all the fingerprints obtained over that period of time. This index is calculated as the arithmetic mean of a set of metrics which evaluate data quality from different perspectives. These metrics can be seen in Tab. 1.

Information is presented to the user through a web interface (ASP.NET Core MVC). The site uses a responsive web design (based on the Bootstrap framework) to allow pages to be displayed in different devices (desktop, mobile, tablets) by automatically adapting its contents to the target screen. Authentication into the system can be done either through a single sign-on approach (using Azure Active Directory credentials), or with a customised username and password (both methods use Microsoft Identity Server as the authorization mechanism).

\section{IMPLEMENTATION ENVIRONMENT}

IN

INDUSTRIAL

The system has been implemented in the installations of a leading manufacturer from the wind energy sector. As a first step, the functionality was included in 4 machine tools with very different characteristics, whose specifications are summarized in Tab. 2.

The monitoring system has been implemented using an industrial PC Beckhoff C6015, which is installed inside the electrical cabinets of each of the machines (Fig. 3a). The $\mathrm{PC}$ is connected to each machine control through Ethernet. In the case of older machines, with Sinumerik 840D Production Line (PL) controllers, no Ethernet connection is available. In these cases, HILSCHNER NL-50 MPI to Ethernet converters have been used (Fig. 3b) after checking that they do not affect monitoring performance. To make available to required variables and allow the monitoring system to collect them at high frequency, the PLC programs of the four machines have been accordingly adapted. It must be highlighted that a library has been developed to facilitate and minimize risks in the modification of machine tool PLC programs.

In collaboration with the operator of each machine tool, the part program defining the Fingerprint test has been adapted for the four machines. Different features like axes names, stroke of the movements, programmed feedrate and machine specific commands have been adjusted according to the respective machine characteristics (Tab. 1).
After the implementation, some validation tests are performed to check that the software is correctly configured, and the defined sequence of movements is appropriate. In addition, the validity of the calculated indicators is evaluated. In this step, feedback of machine tool operator and maintenance technicians is critical to obtain the best results. Fig. 4 shows an example of raw torque data obtained during the positioning of the $\mathrm{X}$ axis of the BOST boring machine. The indicators calculated after this sequence are $34.56 \mathrm{~N} \cdot \mathrm{m}$ of maximum torque and $7.77 \mathrm{~N} \cdot \mathrm{m}$ of torque equivalent to friction.

Once the Fingerprint functionality is ready, it has been included in the weekly maintenance activities of the company so that its periodic execution is guaranteed. This way, the evolution of the different indicators over time can be closely traced and, hence, the condition of the main components of the machines can be controlled. In the first months after system implementation, a learning stage is carried out in which the quality and robustness of the indicators is checked and the thresholds to determine faulty machine tool status are defined. Tab. 3 presents the average and Relative Standard Deviation (RSD) of the indicators calculated for the four machines during the first four months after the implementation of the functionality (from 2021/01/06 to 2021/04/30). It can be observed that the system is able to accurately determine mechanical characteristics of the machine components. This should be highlighted for variables like backlash, which is a micron level resolution characteristic that is accurately determined using and indirect method like the one proposed. Even if further tests will help improving the statistics, most indicators show a robust evolution, with small variation in time $(<20 \%$ of RSD). A few of the KPIs, especially the backlash and inversion peak, present higher RSD values due to their low values of the indicators, which are close to system resolution. The RSD of the indicators should be reduced as far as more test results are included in the study.

The observed robustness has been assumed as enough to determine normality and upper and lower threshold values for the different indicators. These limits will allow identification of anomalous results in future tests and early detection of machine tool performance degradation. As mentioned, due to the early stage of this implementations these limits will be further updated as far as more tests are performed in a short term.

Tab. 2: Machine tools included in the industrial demonstrator.

\begin{tabular}{ccccccc}
\hline Builder & Model & Process & $\begin{array}{c}\text { Number } \\
\text { of axes }\end{array}$ & $\begin{array}{c}\text { Number of } \\
\text { spindles }\end{array}$ & $\begin{array}{c}\text { Working } \\
\text { volume }\end{array}$ & CNC model \\
\hline BOST & BOSTRAM2 & Horizontal Boring & 3 & 1 & $13 \times 4 \times 2.5 \mathrm{~m}^{3}$ & $\begin{array}{c}\text { SIEMENS Sinumerik } \\
840 \mathrm{SL}\end{array}$ \\
BOST & VTL55CY & Vertical Turning & 4 & 1 & $8 \times 13 \times 2 \mathrm{~m}^{3}$ & $\begin{array}{c}\text { SIEMENS Sinumerik } \\
840 \mathrm{SL}\end{array}$ \\
Kehren & Ri12-4 & Vertical grinding & 3 & 1 & $1.5 \times 2 \times 1 \mathrm{~m}^{3}$ & $\begin{array}{c}\text { SIEMENS Sinumerik } \\
840 \mathrm{PL}\end{array}$ \\
PFAUTER & P2800G & Profile grinding & 3 & 2 & $2 \times 1 \times 2 \mathrm{~m}^{3}$ & $\begin{array}{c}\text { SIEMENS Sinumerik } \\
840 D \text { PL }\end{array}$ \\
\hline
\end{tabular}




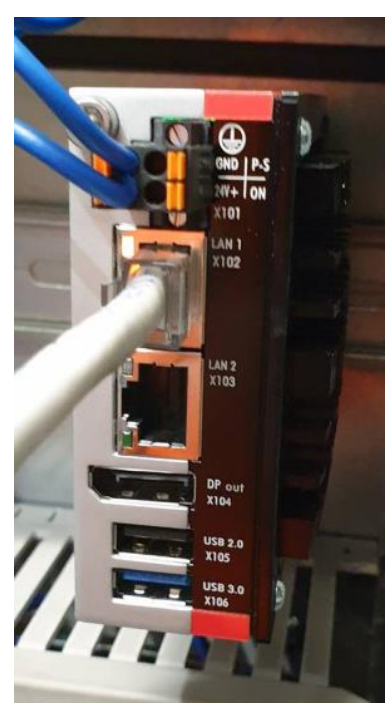

a)

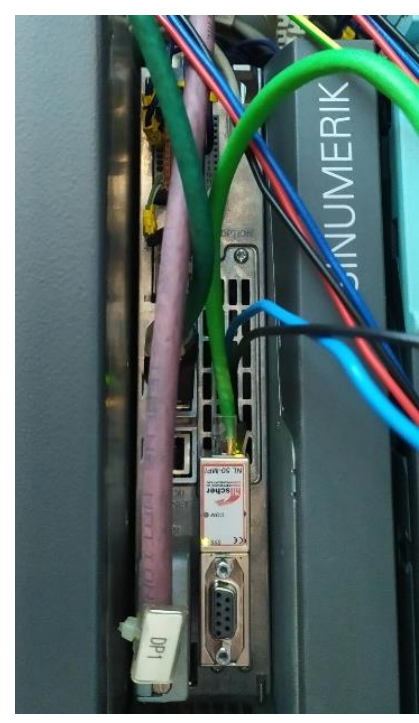

b)
Fig. 3: Hardware used in the implementation: a) Beckhoff C6015 Industrial PC; b) HILSCHNER NL-50 MPI to Ethernet adapter installed in a SIEMENS Sinumerik 840D PL CNC.

Following the implementation approach shown in Fig. 2, the data locally stored in the four machines after each Fingerprint test is sent and stored in an external server. Every time a Fingerprint test is executed and properly updated to the data management system, a notification is sent to the correspondent users. If the uploaded Fingerprint test present anomalies (data quality metrics, extremely deviated KPIs) the notification includes a warning to review the indicators and a request to repeat the test.

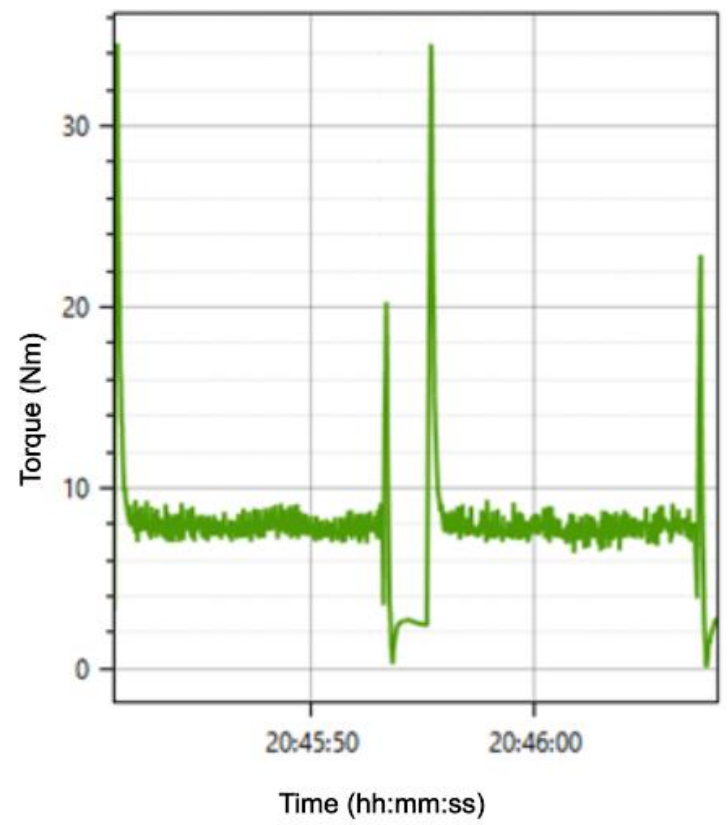

Fig. 4: Torque raw data (N.m) during the positioning sequence of the $X$ axis of the BOST BOSTRAM2 boring machine.

The platform provides a web interface to show fingerprint results through various monitoring dashboards, as it is indicated in Fig. 2. First, results of independent Fingerprints are visualized by plotting values normalized to unity value each KPI nor on spider graphs, including normalized upper limits which have been calculated in the characterisation stage (Fig. 5a). In case any indicator gets close or gets over

Tab. 3: Statistics of the indicators collected during the period from 2021/01/06 to 2021/04/30 for the 4 machine tools included in the demonstration case (RSD: Relative Standard Deviation in \%)

\begin{tabular}{|c|c|c|c|c|c|c|c|c|c|}
\hline \multirow{2}{*}{$\begin{array}{c}\text { Axis/ } \\
\text { Spindle }\end{array}$} & \multirow{2}{*}{ Indicator name } & \multicolumn{2}{|c|}{ BOST BOSTRAM2 } & \multicolumn{2}{|c|}{ BOST VTL55CY } & \multicolumn{2}{|c|}{ KEHREN Ri12-4 } & \multicolumn{2}{|c|}{ PFAUTER P2800G } \\
\hline & & Mean & RSD & Mean & RSD & Mean & RSD & Mean & RSD \\
\hline \multirow{4}{*}{$\mathrm{A} 1$} & Backlash $(\mu \mathrm{m})$ & 15 & 26.7 & 9 & 11.1 & - & - & - & - \\
\hline & Inversion Peak ( $\mu \mathrm{m})$ & 14 & 35.7 & 14 & 7.1 & - & - & - & - \\
\hline & Max. Torque $(\mathrm{N} \cdot \mathrm{m})$ & 37.0 & 4.2 & 33.1 & 1.8 & 710.2 & 11.1 & 33.3 & 8.0 \\
\hline & Friction $(\mathrm{N} \cdot \mathrm{m})$ & 4.4 & 9.8 & 4.2 & 7.0 & 28.9 & 2.4 & 15.5 & 3.1 \\
\hline \multirow{4}{*}{$\mathrm{A} 2$} & Backlash $(\mu \mathrm{m})$ & 17 & 17.6 & 28 & 7.1 & 19 & 57.9 & 100 & 2.0 \\
\hline & Inversion Peak ( $\mu \mathrm{m})$ & 13 & 23.1 & 83 & 10.8 & 10 & 80.0 & 24 & 29.2 \\
\hline & Max. Torque $(\mathrm{N} \cdot \mathrm{m})$ & 35.9 & 4.1 & 47.2 & 11.1 & 60.9 & 23.2 & 7.8 & 4.0 \\
\hline & Friction $(\mathrm{N} \cdot \mathrm{m})$ & 7.9 & 6.2 & 9.9 & 4.1 & 18.8 & 12.6 & 2.3 & 2.9 \\
\hline \multirow{4}{*}{ A3 } & Backlash $(\mu \mathrm{m})$ & 5 & 20.0 & 16 & 6.3 & 1 & 0.0 & 39 & 7.7 \\
\hline & Inversion Peak ( $\mu \mathrm{m})$ & 6 & 16.7 & 4 & 0.0 & 0 & 0.0 & 14 & 21.4 \\
\hline & Max. Torque $(\mathrm{N} \cdot \mathrm{m})$ & 58.6 & 3.2 & 20.2 & 1.1 & 32.3 & 33.7 & 3.5 & 16.0 \\
\hline & Friction $(\mathrm{N} \cdot \mathrm{m})$ & 14.9 & 4.3 & 17.3 & 1.4 & 6.6 & 20.8 & 5.2 & 4.1 \\
\hline \multirow{4}{*}{ A4 } & Backlash $(\mu \mathrm{m})$ & 12 & 8.3 & - & - & - & - & - & - \\
\hline & Inversion Peak $(\mu \mathrm{m})$ & 6 & 50.0 & - & - & - & - & - & - \\
\hline & Max. Torque $(\mathrm{N} \cdot \mathrm{m})$ & 35.1 & 3.2 & - & - & - & - & - & - \\
\hline & Friction $(\mathrm{N} \cdot \mathrm{m})$ & 6.3 & 6.8 & - & - & - & - & - & - \\
\hline S1 & Friction $(\mathrm{N} \cdot \mathrm{m})$ & 22.9 & 8.9 & 24.6 & 3.5 & 1.9 & 8.0 & 3.7 & 13.7 \\
\hline $\mathrm{S} 2$ & Friction $(\mathrm{N} \cdot \mathrm{m})$ & - & - & - & - & - & - & 0.4 & 3.9 \\
\hline
\end{tabular}


the determined limit this will be easily identified and, in addition, the system will send a notification to the correspondent users. Second, the evolution of the KPIs in time can be studied in time-series graphs (Fig. 5b). This allows for deeper analysis of KPIs, including trend detection and possibility to correlate KPI values with maintenance events.
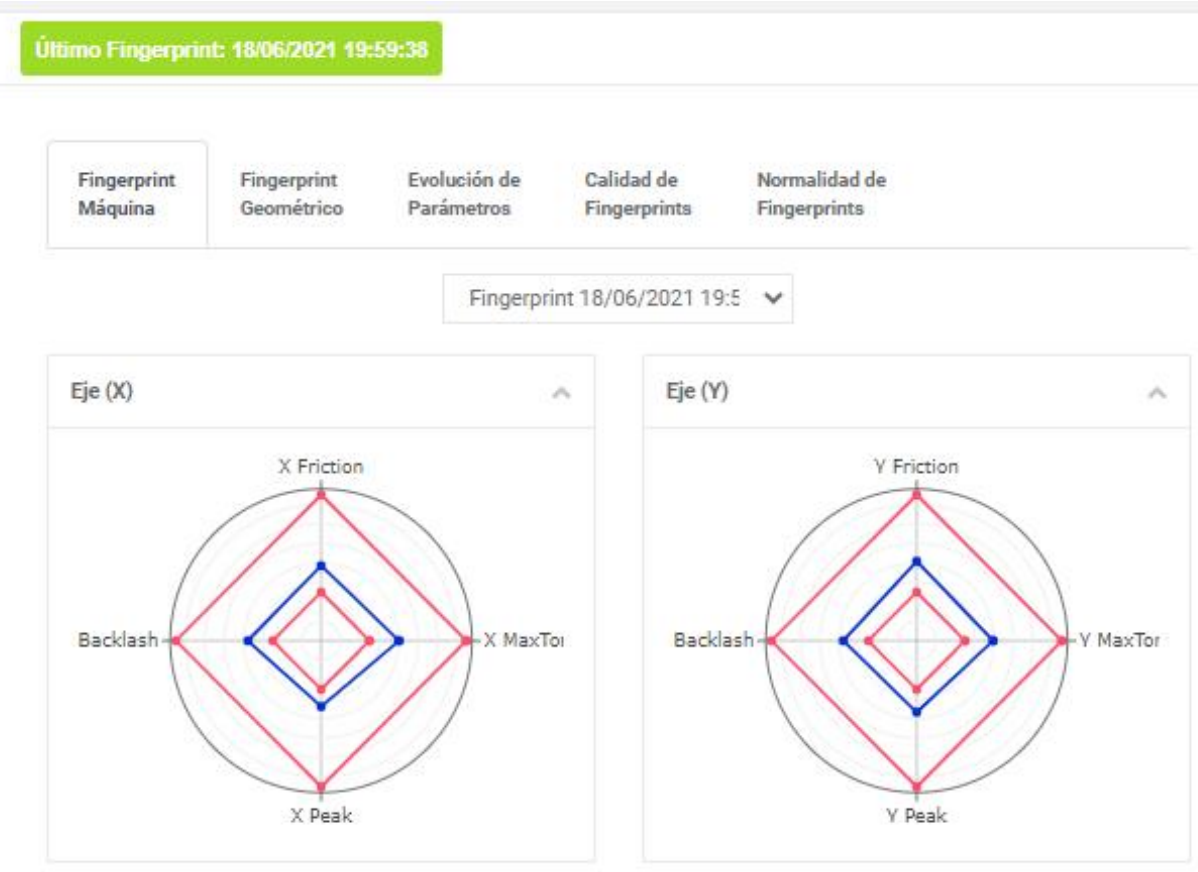

a)

\section{Calidad de \\ ingerprints \\ Normalidad de \\ Fingerprints}

\section{Ültimo Fingerprint: 1806r2021 19:59:38}

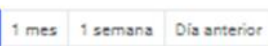

\begin{tabular}{|c|c|c|c|c|}
\hline $\begin{array}{l}\text { Fingerprint } \\
\text { Máquina }\end{array}$ & $\begin{array}{l}\text { Fingerprint } \\
\text { Geométrico }\end{array}$ & $\begin{array}{l}\text { Evolución de } \\
\text { Parámetros }\end{array}$ & $\begin{array}{l}\text { Calidad de } \\
\text { Fingerprints }\end{array}$ & $\begin{array}{l}\text { Normalidad de } \\
\text { Fingerprints }\end{array}$ \\
\hline
\end{tabular}

\section{Parámetros de Fingerprint}

\begin{tabular}{|l|l|}
\hline XXFiction & Aceptar \\
\hline
\end{tabular}

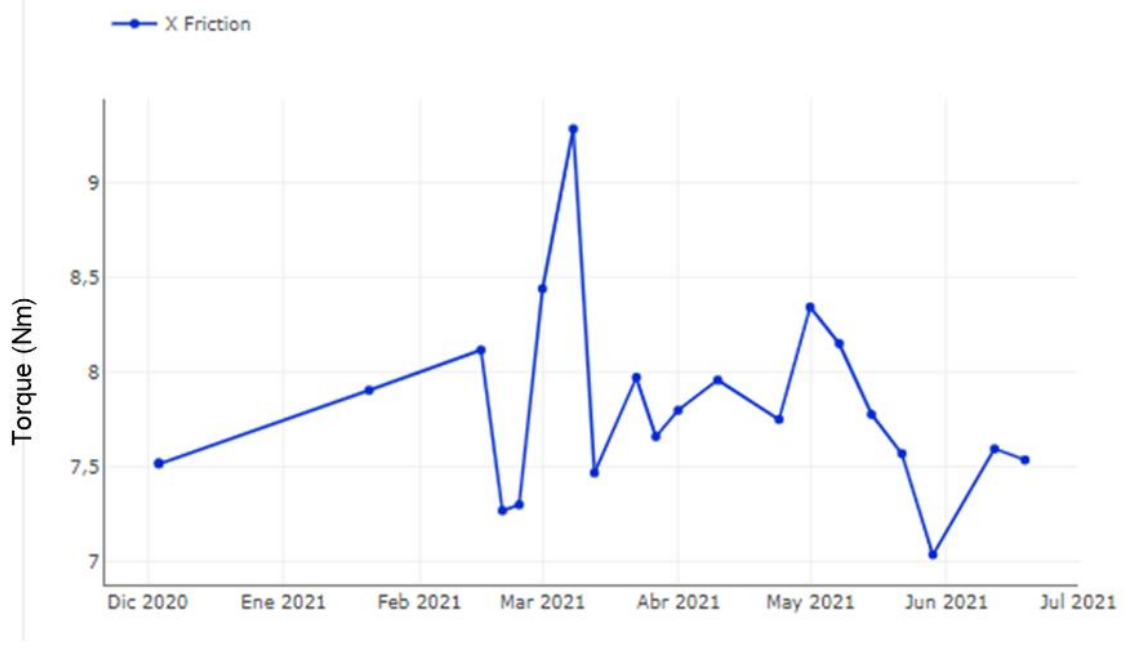

Date (Month Year)

b)

Fig. 5: Fingerprint result visualization at SmartFactoryCell: a) Independent Fingerprint result using spider graphs (KPls normalized to unit value); b) time-series showing KPI evolution.

MM Science Journal | 2021 | NOVEMBER - Special Issue on HSM2021 


\section{CONCLUSIONS AND NEXT STEPS}

A fast and automated machine tool characterization procedure, called Fingerprint, has been developed that allows the determination of KPIs related to the condition of the most critical elements of machine tools. The identification of machine tool condition will serve as a reference for increasing the Overall Equipment Effectiveness (OEE) inside manufacturing companies since it will allow the implementation of preventive maintenance actions. That will minimize production breakdowns, and ensuring optimal manufacturing conditions, towards ZeroDefect-Manufacturing.

A sequence of movements has been defined and implemented through a part program so that the machine operator only needs to load and run it to perform the tests. A complete monitoring and data management infrastructure has been set so that, every time the Fingerprint part program is running, the required data is monitored, appropriately post-processed, managed and visualized. The system sends notifications in case of relevant events (test execution, anomalous test, KPI above defined limits) to the correspondent users.

The Fingerprint functionality has been implemented in 4 machine tools of a real industrial scenario. Different generation machine tools have been addressed to overcome data availability and communication limitations. During the first months after the implementation, in a learning or characterization stage, Fingerprints have been weekly executed in the four machines. An analysis of the obtained indicators shows that the obtained indicators are robust enough to determine normal condition of the machine as well as thresholds that determine anomalous condition.

In the next months, Fingerprint tests will still be executed in a weekly basis by the maintenance personnel of the company with the following objectives: confirm and improve robustness of the calculated indicators, fine tuning of the thresholds, identification of machine faulty condition and correlation of indicator evolution with the performed maintenance actions. To support this work, apart from the possibility to send notifications, the system provides a webbased interface that allows fast overview of Fingerprint results as well as complete study of each indicator evolution.

In addition, further functionalities will be implemented in the use case like the calculation of KPIs linked to spindle condition after the integration of accelerometers and the control of data quality through the defined metrics (Tab. 1).

\section{ACKNOWLEDGMENTS}

The work presented in this paper is part of the research work still in progress in the project InterQ which has received funding from the European Union's Horizon 2020 Research and Innovation Programme under grant agreement No. 958357 and it is an initiative of the Factories-of-the-Future (FoF) Public Private Partnership.

\section{REFERENCES}

[Armendia 2016] Armendia, M., Peysson, F., Euhus, D., Twin-Control: A New Concept Towards Machine Tool Health Management, PHM Society European Conference, 3 (2016).

[Armendia 2019] Armendia, M., Ghassempouri, M., Ozturk, E., Peysson, F., Twin-Control: A Digital Twin Approach to Improve Machine Tools Lifecycle; Springer International Publishing, 2019.

[Cep 2018] Čep, R., Malotova, Š., Kratochvil, J., Stancekova, D., Czan, A., Jakab, T., Diagnosis of machine tool with using Renishaw ball-bar system, MATEC Web of Conferences, 2018.

[Frank 2019] Frank, A., Dalenogare, L., Ayala, N., Industry 4.0 technologies: Implementation patterns in manufacturing companies. International Journal of Production Economics, 210 (2019)

[Khine, 2019] Khine, P. P., \& Wang, Z. (2019). A review of polyglot persistence in the big data world. Information, 10(4), 141.

[Okubo 1982] Okubo N., Yoshida, Y., Hoshi, T., Application of Modal Analysis to Machine Tool Structures, CIRP Annals, Volume 31, Issue 1, 1982, Pages 243-246.

[Psarommatis 2019] Psarommatis, F., May, G., Dreyfus, P.A., Kiritsis, D., Zero defect manufacturing: state-of-the-art review, shortcomings and future directions in research. International Journal of Production Research. 58. 1-17, 2019.

[Schwenke 2008] Schwenke H., Knapp W., Haitjema H., Weckenmann A., Schmitt R., Delbressine F., 2008, Geometric error measurement and compensation of machines-An update, CIRP Annals - Manufacturing Technology, vol.57, pp. 660-675

[Vesely 2009] Vesely, J., Sulitka, M., Machine tool virtual model. MM Science Journal, December 2009.

[Wang 2015] Wang, KS., Li, Z., Braaten, J. et al. Interpretation and compensation of backlash error data in machine centers for intelligent predictive maintenance using ANNs. Adv. Manuf. 3, 97-104 (2015).

[Zheng 2018] Zheng, P., Wang, H., Sang, Z. et al. Smart manufacturing systems for Industry 4.0: Conceptual framework, scenarios, and future perspectives. Front. Mech. Eng. 13, 137-150 (2018).

[Zhong 2017] Zhong, R.Y., Xu, X., Klotz, E., Newman, S.T., Intelligent Manufacturing in the Context of Industry 4.0: A Review, Engineering, Volume 3, Issue 5, 2017, Pages 616630, ISSN 2095-8099.

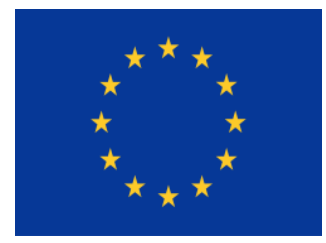

